\title{
LETRAMENTO LITERÁRIO AFRODESCENDENTE: ENSINO-APRENDIZAGEM E FORMAÇÃO DE PROFESSORES
}

\author{
Prof. Dr. Murilo da Costa Ferreira
}

RESUMO: O presente trabalho vai ao encontro das expectativas criadas pela promulgação da Lei 10.639/03, que institui a obrigatoriedade do ensino de História e Cultura Africana e Afrobrasileira nas escolas privada e pública brasileiras. O trabalho, conduzido pelo grupo de pesquisa Educação Literária Afrodescendente $(\mathrm{CNPq} / \mathrm{UNEB})$, também procurou e procurará elaborar um levantamento e a análise do tratamento que recebe a literatura correspondente a temáticas que abranjam assuntos literários africanos de língua portuguesa (Angola, Moçambique, Cabo Verde, São Tomé, Guiné-Bissau e Príncipe) e afro-brasileiros e que não estão incluídos nos materiais didáticos e paradidáticos no contexto educacional brasileiro. Para alcançar os objetivos desta Lei, é preciso haver profissionais com formação adequada para tratar cientificamente das diversas histórias e culturas do Continente Africano, bem como de suas heranças no cotidiano brasileiro. Assim, o que poderá resultar desta pesquisa é a recondução positiva da democracia brasileira, especialmente no que tange à redução da discriminação racial no país.

PALAVRAS-CHAVE: Afrodescendente, literatura, educação, letramento.

\begin{abstract}
This work will meet the expectations created by the promulgation of the Law 10639/03, which establishes the obligation of teaching history and culture of African and AfroBrazilians both in private and public schools in Brazil. This work, conducted by the research group Afrobazilian Literary Education (CNPq / UNEB), also sought and will prepare a survey and analysis of the treatment that relevant literature covering the literary subject matters of African Portuguese (Angola, Mozambique, Cape Verde, Sao Tome, Principe and Guinea Bissau) and african-Brazilians, which are not included in didatic materials in Brazilian educational context. To achieve the objectives of this law, there must be professionals with adequate training to treat scientifically the various histories and cultures of the African continent, as well as their inheritance in the Brazilian daily. So, what can result from this research is the positive extension of Brazilian democracy, especially in regard to the reduction of racial discrimination in the country.
\end{abstract}

KEYWORDS: African descent, literature, education, literacy.

Em estreita conexão com o ensino da literatura na escola, estão questões como: quem determina o programa de estudos, como, sob que influências, com que "produto" por objetivo? Qual é o papel dos exames e que tipo de conhecimento se procura testar? Isso leva, por sua vez, à questão relativa aos métodos pedagógicos e ao tipo de saber construído nas aulas de literatura: será seu objetivo criar consumidores, produtores de literatura ou ambos? Que teorias orientam e fundamentam a Letramento Literário na 
prática cotidiana? Como lidar com diferenças históricas, princípios filosóficos e influências ideológicas?

Existe um acervo considerável de obras sobre produção de textos, leitura literária e leitura como hábito e habilidade em diversas fases de escolaridade. No entanto, para definir o perfil e os componentes da literatura na escola, será necessário rever a percepção da disciplina pelos sujeitos envolvidos no processo de educar para a/pela literatura.

O Letramento Literário como uma representação cultural é essencial ao processo de educar sujeitos sociais, por se tratar de um estudo que se sustenta na multidisciplinaridade composta pelos estudos da linguagem e invadida, recentemente, de forma sistemática, pelos estudos culturais, que indicam uma mudança de ênfase em certas características sócio-culturais e político-pedagógicas. Daí decorre que, por configurar um conhecimento fronteiriço (Cf. Bhabha, 1998), o Letramento Literário pode ter um papel central na formação sócio-política dos presentes e futuros cidadãos da sociedade brasileira.

Tradicionalmente, o paradigma observado na educação literária brasileira (LeahyDios, 2000) é o modelo positivista calcado em história literária, predominantemente ocidental, privilegiando uma objetividade canônica, ou seja, um modelo sistematizado e descritivo, exigindo o domínio de grandes quantidades de conteúdo.

Como em vários países, no Brasil a literatura é um dos assuntos estudados no ensino médio, contida na disciplina oficial de língua portuguesa, com objetivos, conteúdos, modos de avaliação e resultados esperados, pré-determinados.

Por conter uma complexidade de estudos, a literatura é uma instituição social, utilizando como meio a linguagem, como modo de criação social (Cf. Aguiar e Silva, 1973). Ao mesmo tempo em que lida com o sensorial, o emocional e o racional de indivíduos e de grupos sociais, ela atua na comunicação intercultural entre nações e entre povos.

Os estudos da arte literária na escola brasileira, em conexão com os estudos de língua portuguesa, dependendo da orientação político-pedagógica de um dado momento 
no tempo e no espaço, se apóiam abertamente na contextualização histórico-cultural, segundo métodos positivistas.

Partindo desses pressupostos, é preciso observar que o Letramento Literário se submete a imposições verticais, tais como programas e requisitos de avaliação. Uma análise de sua realização como parte do processo educativo requer a observação das ações pedagógicas em salas de aula de literatura; requer também que se ouça o que alunos e professores têm a dizer, sendo importante a forma de interação que ela mantém com outras disciplinas de cunho social, visando à produção de conhecimento relevante para indivíduos e grupos sociais.

Pertinente se faz ressaltar que o Letramento Literário terá a sua presença atuante na licenciatura do Curso de Letras. Isto porque o Curso de Letras apresenta dificuldades de articulação entre o saber teórico fragmentado transmitido aos estudantes e o conhecimento específico com que devem trabalhar em suas próprias salas de aula ao se licenciarem. Isto exige que pensemos acerca da vinculação de uma teorização da literatura com os estudos culturais, de um lado, e, de outro, com a realidade pedagógica das escolas para as quais se formam professor.

Os estudantes de Letras aprendem fatos históricos, econômicos, sócio-políticos e biográficos relativos à literatura; além disso, leem determinados textos, analisam certos autores, períodos e gêneros literários, sem receber informação suficiente acerca de teorias críticas literárias, das escolas de pensamento que permitem diferentes leituras, interpretações e dialogicidades entre texto, leitor e sociedade. Não faz parte dos currículos o processo de permitir aos alunos acesso às condições de produção do conhecimento, aos modos de leitura, consequentemente impedindo-os de participar ativamente na sociedade, para poder intervir nos discursos dominantes de sua cultura. A iniciação dos futuros professores no estudo das disciplinas pedagógicas é caracterizada pela ideia preconcebida de que tais disciplinas carecem de importância, constituindo-se em mera formalidade que os separa de seus diplomas, centrada em pragmatismo tecnicista com receitas e regras didáticas. Frequentemente, graduandos de Letras expressam surpresa por encontrar nas faculdades de Educação uma agenda de engajamento político até então rara em sua formação acadêmica. Sentimos a necessidade de conhecer o papel da literatura como uma matéria de estudo para o ensino 
médio no Brasil, assim como as influências que a disciplina vem sofrendo em sua história contemporânea. Para que seja possível reescrever essa história e gerar a inclusão nos estudos literários da cultural literária do afro-brasileiro, visando a uma influência politicamente significativa nos tempos atuais, é preciso saber que formas tomam a disciplina em questão.

A lacuna entre o conhecimento específico, construído no domínio de língua e literatura como disciplinas acadêmicas, e a construção de tal conhecimento, na forma de material problematizado para uso em salas de aula, se dá pela falta de elementos relevantes ao compromisso político indispensável ao exercício do magistério dentro das escolas e nas práticas sociais. Conscientizar futuros professores de literatura do compromisso com a produção de um conhecimento que possa contribuir para uma sociedade menos desigual significa trabalhar para que professores de literatura sejam politicamente conscientes em sua prática, com a percepção clara de que educar é uma instituição política. Isto também é lícito quando nos referimos ao alunado. Dele é esperado que adquira experiência literária (modelo implícito) ou conhecimento literário (modelo explícito). Em ambos os casos, não só estão professores despreparados para encorajar a variedade de práticas críticas em seus alunos, como também existe uma causa nítida e uma consequência mais clara ainda para tal problema: os alunos não são estimulados a problematizar questões literárias, porque não lhes é dado acesso aos instrumentos que os poderia liberar como críticos, pensadores e fazedores; não conhecem os códigos em que se assenta a produção textual. No entanto, segundo Paulo Freire (1998), todo ser humano, não interessa quão submerso na cultura do silêncio, é capaz de olhar criticamente para o mundo em um encontro dialógico com os outros, desde que as ferramentas próprias lhe sejam dadas para a percepção gradual da realidade pessoal e social e suas contradições.

Apesar da satisfação que professores e alunos possam ter com a criação ou o aumento da subjetividade social e pessoal, exames tradicionais ainda exigem a mensuração das habilidades e da competência para a vida adulta dentro de um perfil de "manufatura da permissão", de submissão acrítica à autoridade de forma que a educação continue sendo um sistema de ignorância imposta (Cf. Said, 1995).

\section{Pluralidade Cultural: uma meta a ser atingida}


O Ministério da Educação, durante a década de 90, elaborou os Parâmetros Curriculares Nacionais (PCNs) que são princípios que norteiam o currículo das escolas brasileiras. A idéia central dos PCNs é que a educação fundamental se oriente por valores e por uma visão do mundo voltada para a cidadania, para a justiça social, para o reconhecimento e a apreciação da diversidade cultural, para os direitos humanos, para a participação de todos nas decisões públicas e coletivas. A tarefa educacional deve começar desde a infância, encaminhando objetivos éticos mediadores da relação entre educação e conhecimentos científicos, tecnológicos e da cultura social em que vivemos.

Esta noção implica em uma afirmação da diversidade cultural que, por sua vez, remete à noção de multiculturalismo, como também de pluri-etnicidade.

Há, principalmente, duas noções que se atraem e se repelem contidas na expressão pluralidade cultural. A primeira indica a acepção de crítica ao preconceito, à discriminação e ao racismo; a segunda, de valorização construtiva da multiplicidade de povos, culturas e tradições existentes no Brasil, ainda não suficientemente conhecidos e estudados no sistema escolar do país, muitas vezes sequer reconhecidos. Sabemos das dificuldades em formular materiais didáticos que analisem e evidenciem as várias formas de discriminação e racismo, ou mesmo, a relação estreita e insuficientemente estudada entre desigualdade social e discriminação e o direito à diferença. Trata-se de temas complexos, que levantam muitas emoções, os quais raramente são examinados objetivamente e de forma qualificada.

Afirmar o direito à diferença e à identidade é um dos mais importantes imperativos da luta pela dignidade humana, pois, desta forma, se oportuniza o direito à igualdade sócio-econômica. No sistema educacional é importante transmitir a história da conquista desse direito pela humanidade tão importante, não só para a população afro-brasileira, como também para os direitos indígenas, das mulheres e dos homossexuais.

No universo cultural brasileiro em questão, revelou-se a ideia de uniformização cultural, racial e/ou étnica como necessária para se construir a identidade brasileira, reduzindo-a a uma única língua, a uma religião, a um modo de ser. Num país de multiplicidade étnica e cultural, com a metade da população de origem não européia 
(africana, indígena, asiática ou outra), a uniformidade porventura existente deve ser explicada como resultado de um processo colonial e escravocrata, autoritário e europocêntrico.

Sabemos que o Brasil está muito longe de ser uma democracia racial. Cerca de mais de $40 \%$ da população brasileira tem origem africana e ocupa o segmento mais baixo sócio-econômico da pirâmide social brasileira. Os que nos censos do IBGE se declaram pardos e pretos têm rendimentos sensivelmente inferiores aos dos outros, para um mesmo nível educacional - calcula-se que ganhem aproximadamente $80 \%$ do que ganham os brancos. Isto decorre das dificuldades de acesso às oportunidades educacionais e à política.

Assim, incluir no currículo escolar elementos para construir paulatinamente um quadro de estudos literário, sociológico, antropológico e histórico da sociedade brasileira nos seus aspectos culturais e históricos africanos em África e os seus descendentes no Brasil, é fundamental para mudar atitudes preconceituosas, transmitindo às crianças e aos adolescentes conhecimentos que permitam uma crença arraigada na liberdade, no respeito à alteridade, na tolerância, na apreciação de tradições e valores alheios.

\section{Aprendizagem e Ensino das Africanidades Brasileiras e o Ensino da}

\section{Literatura}

Ao mencionarmos africanidades brasileiras (Cf.Silva, 2001), estamos nos referindo às raízes da cultura brasileira que têm origem africana. Em outras palavras, referem-se aos modos de ser, de viver, de organizar suas lutas, próprios dos negros brasileiros, como também, às marcas da cultura africana que, independentemente da origem étnica de cada brasileiro, fazem parte do seu cotidiano.

Africanidades Brasileiras ultrapassam o dado ou o evento material, como um prato de sarapatel, uma congada, uma apresentação de capoeira. Elas se constituem nos processos que geraram tais dados e eventos, hoje incorporados pela sociedade brasileira. Também se constituem dos valores que motivaram tais processos e dos que deles resultaram. 
As Africanidades Brasileiras vêm sendo elaboradas há quase cinco séculos, na medida em que os africanos escravizados e seus descendentes, ao participar da construção da nação brasileira, vão deixando nos outros grupos étnicos com que convivem suas influências e, ao mesmo tempo, recebem e incorporam as daqueles. Portanto, estudar as Africanidades Brasileiras significa tomar conhecimento, observar, analisar um jeito peculiar de ver a vida, o mundo, o trabalho, de conviver e de lutar pela dignidade própria, bem como pela de todos os descendentes de africanos, mais ainda, de todos que a sociedade marginaliza. Significa também conhecer e compreender os trabalhos e criatividade dos africanos e de seus descendentes no Brasil e de situar tais produções na construção da nação brasileira.

As propostas de ações pedagógicas interétnicas têm sido múltiplas a partir das duas últimas décadas do século $\mathrm{XX}$, constituindo-se em iniciativas de diversos setores da sociedade brasileira de implantação no ensino fundamental e médio dos assuntos africanos e afro-brasileiros. Assim, diversos estudos, desde então, se incumbiram de analisar e de propor aos professores e estudantes a utilização crítica do material pedagógico aplicado em sala de aula. As razões são as mais diversas, mas, talvez, a mais contundente delas esteja na exclusão da história e da cultura próprias do afrobrasileiro do processo educativo tanto dos livros didáticos de literaturas do ensino médio como do Curso de Letras. Desta maneira, equivocadamente, seus antepassados são retratados apenas como "escravos", persistindo-se em ocultar a contribuição do negro na formação histórica e civilizatória da sociedade brasileira e universalmente para o ser humano. Se em termos de estudos literários, por exemplo, de um lado, a presença do negro se reduz (no conto, romance, novela, teatro, etc.) a um personagem, redundantemente, submisso, apagado, invisível e impronunciável, de outro, no cenário dos escritores afro-brasileiros, distingue-se o catarinense simbolista Cruz e Sousa, a título de ilustração, como o artista que merece destaque canônico nos livros didáticos de literaturas. No entanto, o erro persiste: a crítica literária rasura o vínculo dialético entre a identidade histórico-cultural e o texto literário, sugerindo que as injunções sociais da discriminação racial determinam, preponderantemente, a confecção de sua obra. Ou, de um outro modo interpretativo, que sua produção literária "evolui" ao se tornar "universalizante", sugerindo, implicitamente, o apagamento dos traços culturais negros 
de sua trajetória literária, na medida em que incorpore os traços culturais "universalizantes" do branco europeu.

Contrariamente a estas abordagens eurocêntricas da história e da literatura afrobrasileiras, a nossa atenção está voltada não apenas para o preconceito racial que atinge a população negra (infantil e adolescente, principalmente) nas escolas brasileiras, mas também nos preocupamos com as graves distorções da realidade histórica dos povos africanos e do negro brasileiro que tradicionalmente orientam o ensino de forma geral. Omitindo, distorcendo e menosprezando, o sistema educacional acaba privando a criança e o adolescente do conhecimento da literatura produzida pelos negros no Brasil e da maneira pela qual ela constitui uma experiência histórica, filosófica e cultural da maioria brasileira de origem africana, construtora da sociedade e da identidade nacional.

Necessitamos da existência de balizadores teóricos de construção de uma nova maneira de "olhar" a produção literária afro-brasileira. Sabemos como esta e outras contribuições teóricas podem avançar a visão pluralista da realidade brasileira. Entretanto, acreditamos que o tema da pluralidade somente poderá se tornar eficaz se formos além das denúncias de distorções do ensino brasileiro. É necessário que transformemos o espaço escolar "num espelho da riqueza humana" e, sobretudo, garantamos a elaboração de novos materiais didáticos para que o afro-brasileiro possa se integrar no processo educativo. Para ter eficácia, o processo pedagógico precisa partir do universo cultural do aluno. Se cada grupo social tem a sua realidade, ou seja, sua crença, seus valores, sua particular filosofia de vida, (isto) significa trazer para dentro da escola as diferenças sociais e culturais, e explicitá-las.

\section{REFERÊNCIAS}

BHABHA, Homi K. O local da cultura. Belo Horizonte: Ed. UFMG, 1998.

GRAMSCI, Antonio. Cadernos do Cárcere. São Paulo: Civilização Brasileira, 2001.

LEAHY-DIOS, Cyana. Educação literária como metáfora social: desvios e rumos. Niterói: EdUFF, 2000. 
SAID, Edward W. Cultura e Imperialismo. São Paulo: Companhia das Letras, 1995.

SILVA, Petronillha Beatriz Gonçalves. "Aprendizagem e ensino das africanidades brasileiras". In Kabengele Munanga: Superando o racismo na escola. Brasília: Ministério da Educação, 2001.

AGUIAR e SILVA, Vitor Manuel de. Teoria da Literatura. Coimbra: Livraria Almendina, 1973.

RECEBIDO EM: 04 de maio de 2011 APROVADO EM: 10 de junho de 2011 